\title{
Release and Deployment management process for IT services
}

\author{
Maqhbool Jameel Ahmed, Dr. Katuru Phani Raja Kumar
}

\begin{abstract}
The main objective of this project is to come up with a Release and Deployment Management Process that can add value to customer products and enhance the operations. The scope of this paper is limited to the definition of different programs, Risk and Security, Team Establishment and Logistics, and Creation of the Build and Testing Documentation that are vital. Process integration in this Release and Deployment Management remains critical in understanding different activities that will enhance security. Release and Deployment Management is a factor of capacity management, problem management, availability management, service management, change management, and service desk. There are also life-cycle phases that are critical in the Release and Deployment Management including initiation, concept, analysis, design, build, test, deploy, closure, and benefits.
\end{abstract}

Keywords - Bug, Break fix, Change Request, Change Management, Cutover Verification Testing, Global Network Operations Centre, Major Release. Minor Release, Product Verification testing Release, Service Desk.

\section{I.INTRODUCTION}

The process of management of release and deployment is within the transition stages of service of an ITIL life cycle service. The process involves the transition of services to a live environment that is operational. The schedules control the builds and plans of the organization release and test as they transit their services to operate.

According to Guo et al. (2016), the primary goal is to create value for the clients and ensure that the service can be handed over to operations of services. The packages designed at the end of design of functions are implemented, built, and tested in the transition of services within the stages and while releasing and deploying the process of management. Deployment of the releases to production and the establishment of active service use are among the goals of the process.

\section{OBJECTIVE}

Release and Deployment Management is to deploy releases into production and establish effective use of the service in order to deliver value to the customer and be able to handover to service operations.

Maqhbool Jameel Ahmed, Director, Tech Mahindra America's Inc. Plano, Texas, United States.

Dr. Katuru Phani Raja Kumar, Project Manager, Tech Mahindra Americas, USA. Plano, Texas, United States.
1) To ensure the satisfaction of the users, staff of service management, and customers.

2) Enabling by providing clear and comprehensive release and deployment plans that enable the customer and business change projects to align their activities with these plans.

3) Built a release package that can be installed, tested and deployed efficiently to a deployment group or target environment successfully and on schedule.

4) There is minimal unpredicted impact on the production services, operations and support organization and Improving consistency in implementation approach across the business change, service teams, suppliers and customers.

\section{III.WHAT IS THE RELEASE?}

A release is a package that seeks to deliver services to customers in the end, depending on what they require. According to Manglik et al. (2016), it is a collection of software, hardware, documentation, and other components that enhance the implementation of more than one change that has been approved to the services of information technology. The overall package of service involves various assets interconnected to each other that delivers value to customers may also indicate release. All the contents of a release are deployed, tested and managed as single entities. Thus, a release is made up of various services, assets, and components. All the elements of a package of service are meaningful if they are served to the customer together. A provider of service usually manages a release as one single entity. 


\section{IV.PROCESS INTEGRATION}

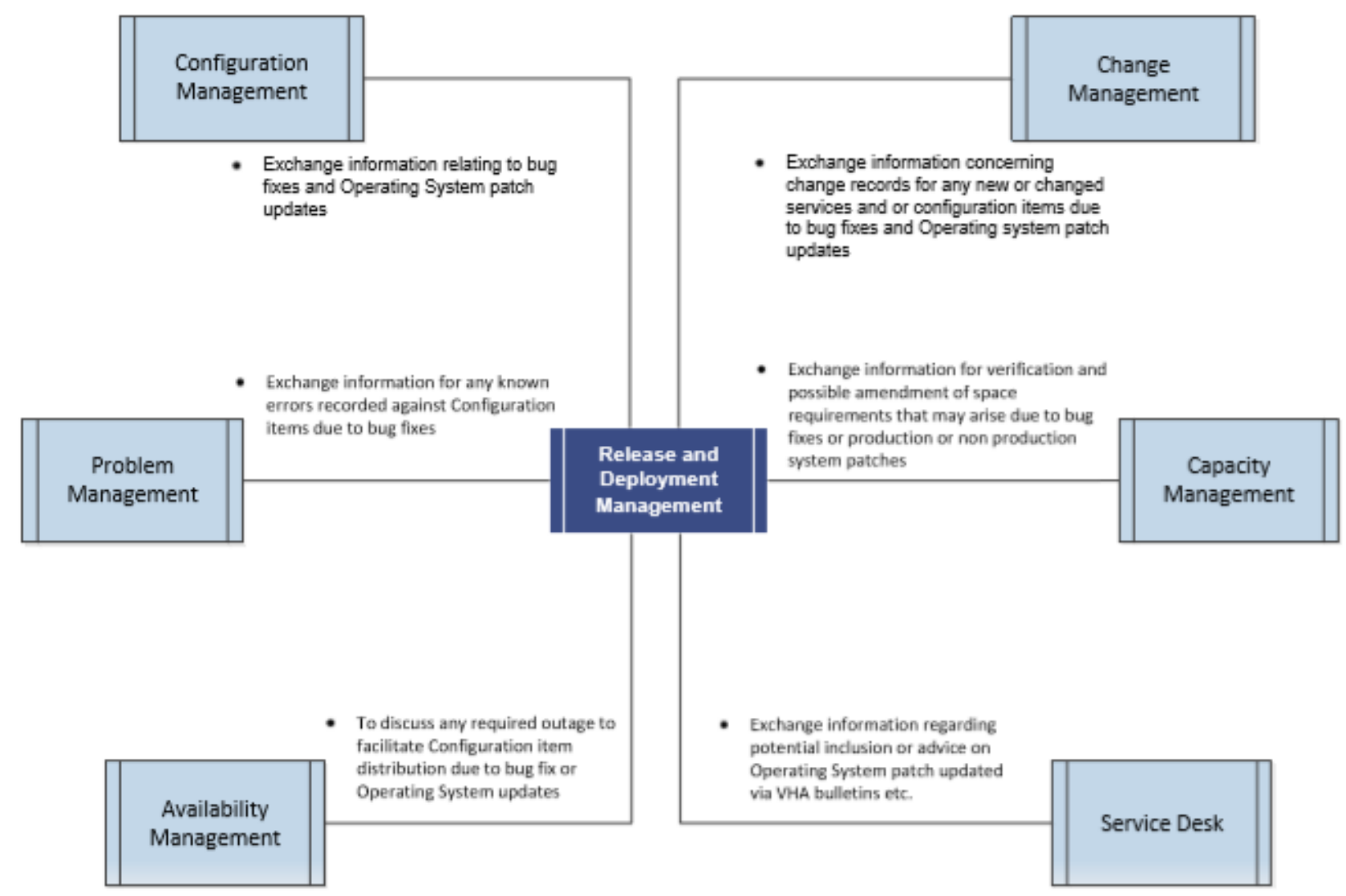

Fig 1: Integration of the Process

A. Configuration Management

Exchange information related to patch updates of the operating system bug fixes.

\section{B. Problem Management}

Information exchanges for errors recorded and known against the configuration items because of bug fixes.

\section{Availability Management}

Discusses required outages to facilitate the shape and distribution of elements because of updates of the operating system or bug fix.

D. Service desk

Exchanges information that regards all inclusions that are potential and advises on the patch of system operation.

\section{E. Capacity Management}

Exchanges information for verification and amendment of the requirements of space which originate from bug fixes or the patches in non-production and production

\section{F. Change Management}

Exchanges information that concerns records of change for new or changed services or configuration items because of bug fixes and updates of the operating system.

\section{DESCRIPTION OF LIFE CYCLE PROCESS}

The framework seeks to define the lifecycle for developing systems that are often used for IT projects (Mantripragada et al., 2016). Some of the framework's vital features are the approval gates and a checklist at the end of the phase. The framework categorizes the aspects into nine broad categories to enhance the transition from one stage to the next. The phases are: 


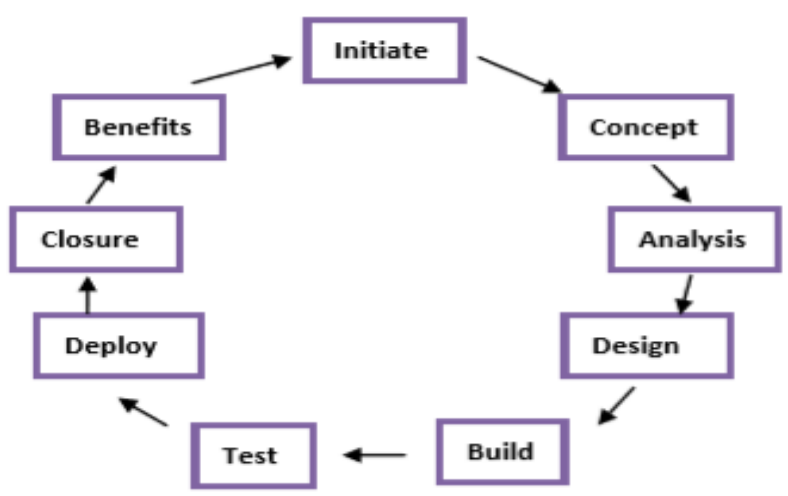

Fig 2: Phases of the life cycle of a software

\section{A. Initiate}

The stage involves the generation of business ideas, identification of the problems in a business, definition of the goals of the business, and formalization of requests for improvements and solutions.

\section{B. Concept}

It reviews all ideas and prepares proposals of projects that comprise the benefits of business, options of the solution, assessment of risks, costs, and higher levels of project plans.

\section{Analysis}

It confirms whether completion of a given project is viable within the time frame, budget, and the available resources while respecting technology and business.

\section{Design}

Creates a design for the elements of requirements using the identified needs, the architecture of the solution, and analysis that is approved.

\section{E. Build}

It involves the development of software's or processes of change, products, or services.

\section{F. Test}

It allows the running of tests to determine and verify the completeness and accuracy of solutions.

\section{G. Deploy}

It involves implementing software's or processes of change and products in live environments and how they are available to different users.

\section{H. Closure}

During this phase, results are verified in terms of their quality, duration of cost, and the timelines.

\section{PLANNING THE RELEASE}

The process of release scheduling and planning involves determining the desired outcomes for more than one major release and maximization of the chances of achievement. Passmore, (2016) argues that, it involves establishing specific, measurable, and clear goals.

A release describes the portion of service or Application change or IT Infrastructure change performed on the IT Service Environment. It can also be a code change which can be deployed into Production.

The process of planning a release occurs in two levels. The first one is across several releases and in a single release. The former may be done appropriately with a roadmap for the product (Pillay et al., 2018). A road map that is goal-oriented indicates the benefits that are desired or the outcomes of each release. Some of the goals are acquiring new users, reducing costs, and removing debts that are technical and proof of the product in the future.

There are different types of Release classification based on the scope and prioritization of project impacts.

1) Pricing Releases -Are high-priority, high-impact pricing changes deployed each month.

2) Maintenance (Break fixes) - These include System break fixes (Siebel, ASAP, Mediation etc), PIE releases, Hot fixes and minor enhancements. Weekly windows will be made available for these releases.

3) Minor release items - These release items will cover most of the release units currently being classified as Capacity and Stand Alone units. These will be deployed on a daily basis. 
4) Major release items - These are major changes and high-impact projects, bundled together or standalone and deployed in one go, causing significant increase in revenue, volumes, and scaling. They will be deployed on Bi-monthly basis.

5) Emergency CRs - All Emergency CRs that need to be deployed immediately to restore a service so that Operations are not impacted. These will be deployed at any point of time.

Any approved project or maintenance bundle that is scheduled to be deployed during the monthly release window are referred to a $\mathrm{ON}$ release. Any project or maintenance that is scheduled on any day of the month, outside the monthly release window are referred to as OFF release.

\section{A. Release Item}

A release item (or Project) is a collection of one or more deliverables into Production, each deliverable dependent on the others.

\section{B. Release Registration}

Each release item is registered with the Release planning manager, through the Release Request Form. This form includes details of the technical impact, business impact, systems impacted, outage duration, risk involved and stakeholders.

The details from RR form are recorded in the release request list, against a unique Registration number. This number is used to track the release item through the deployment schedule of the different deliverables.

\section{Release Unit and Identification}

A release unit describes the portion of service or Application change or IT Infrastructure change performed on the IT Service Environment. It can also be a code change which can be deployed into production. Common options for release and deployment that are considered in service design are discussed below. It is important to understand the patterns of business activity (PBA) and user profiles when planning and designing the release units.

This can also be done in a phased Approach. A portion of service is deployed initially, and then this operation is repeated for subsequently via a scheduled rollout plan. Below diagram provides the details on the phase approach. Each Phase has been identified as Release unit.

\section{Release Calendar}

The Release Calendar is a planned operational change deployed/rolled out in production, in controlled manner, ensuring minimal outages and impacts to systems. The plan for deployment is intended to group together release items of similar or dissimilar type (Category of the release item viz. capacity, stand alone, break fix, pricing etc), which can coexist without impacting each other. It also takes into account the Business priorities, Technical limitations and Resourcing

\section{E. Release Approval}

The classification of a release item into Break fix, Minor or Major Category and its subsequent deployment, will be approved by the weekly release deployment dependencies workshop. The forum will comprise technical team, business representatives and select architects. Post-classification and approval, the release calendar will be published to a wider audience for review and consent.

1) Each Release Item must have a unique release number and predefined Naming Convention.

2) Each Release Unit must be deployed during the release calendar window. All the calendar's need to be consolidated and accounted in the overall calendar.

3) Each Release Unit must be approved before moving to production.

\section{F. Deployment Planning}

This phase involves planning the activities to rollout a release into operations and managed by a release manager. It involves.

1) Providing Deployment schedule for the impacted components

2) Identifying technical dependencies for the final implementation

3) Identifying technical dependencies for preproduction deployment Communication

4) Identifying/maintain the stakeholders (Business and Operations) impacted by the change.

5) Training People impacted by the change. 


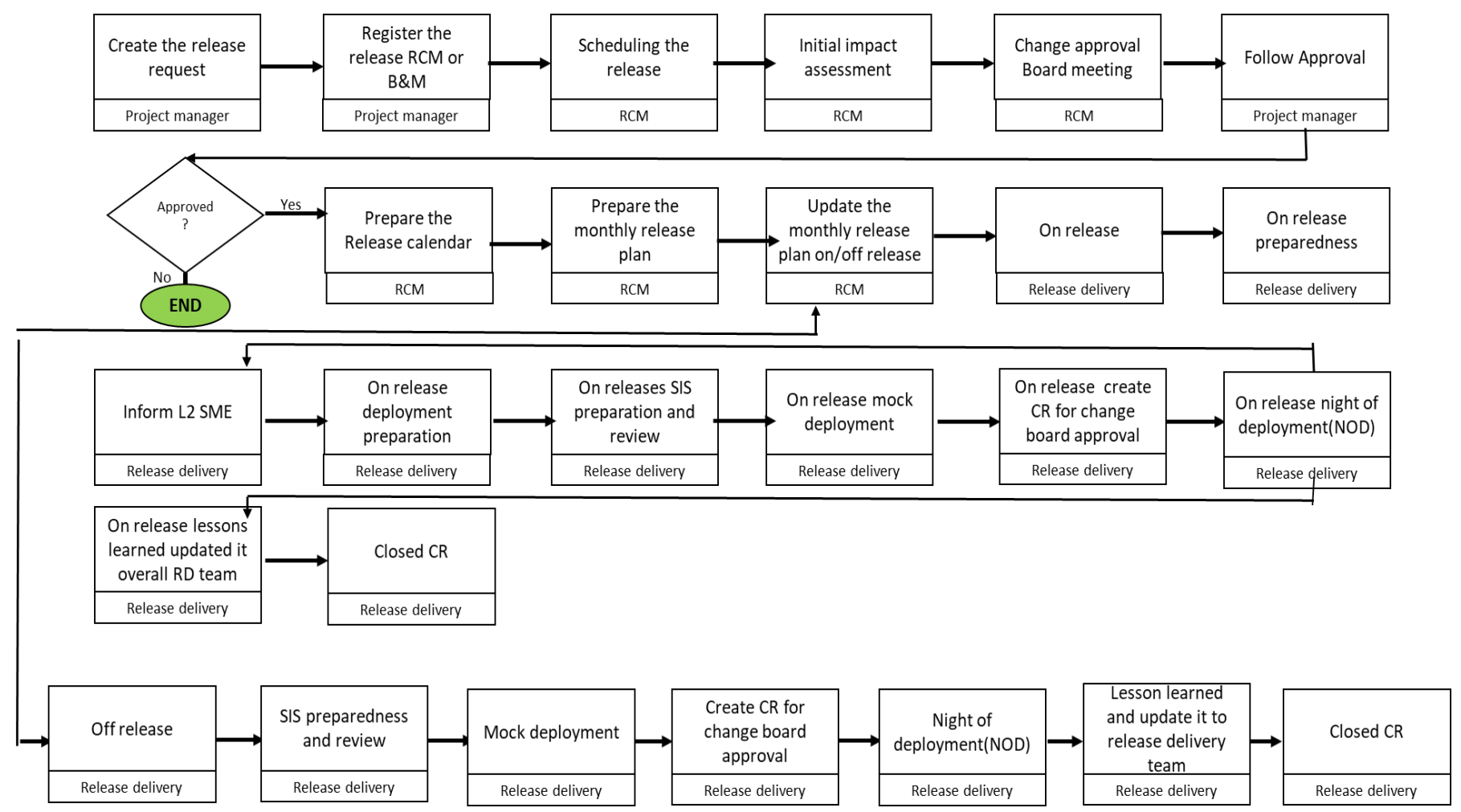

Fig 3: Detail process release flow

\section{RELEASE CHANGE MANAGEMENT PROCESS}

The project manager completes and submits requests of entry in the log of RCM. They also provide any information about RCM and resubmit claims. The release management then opens and reviews the applications that were entered, adds them to the RCM agenda and meetings, and sends out invitations. They also discuss the items in the RCM meeting, publish notes for RCM meetings and update the entire release management documentation. Once the above is completed, the teams of supply will review requests that are open in the pre-RCM meeting, ensure the RCM requests are approved, and ensure they are ready for RCM meetings.

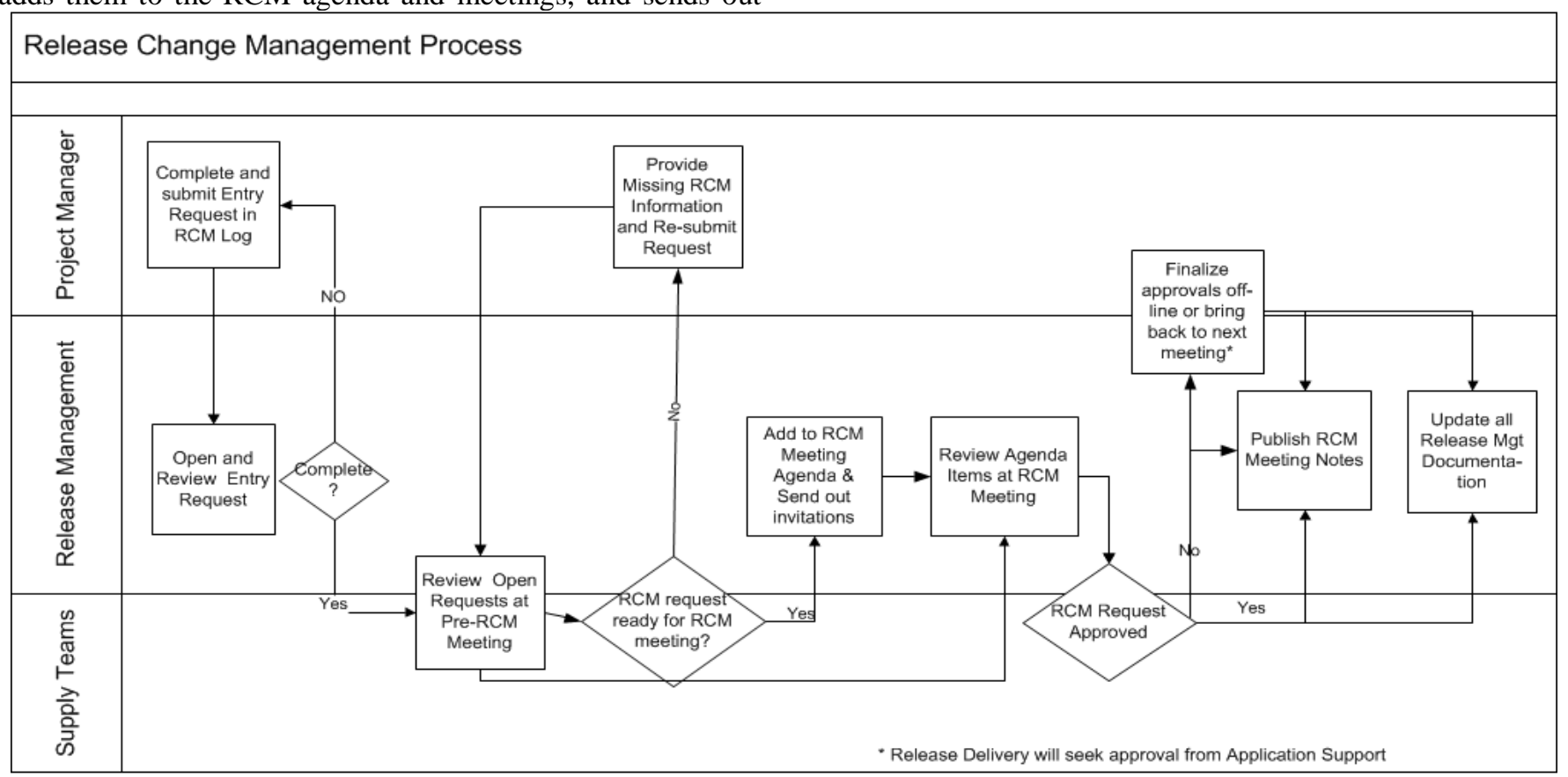

Fig 4: Release change management Process 


\section{MAINTENANCE AND BUG FIXES}

Maintenance of software's involves modification of products of software to correct faults and enhance performance. Singh et al. (2017) proposes that, the efforts to support enhance non-corrective actions. Users perpetuate the perception through the submission of reports on problems.

The maintenance and bug fix processes are summarized in the diagram below.

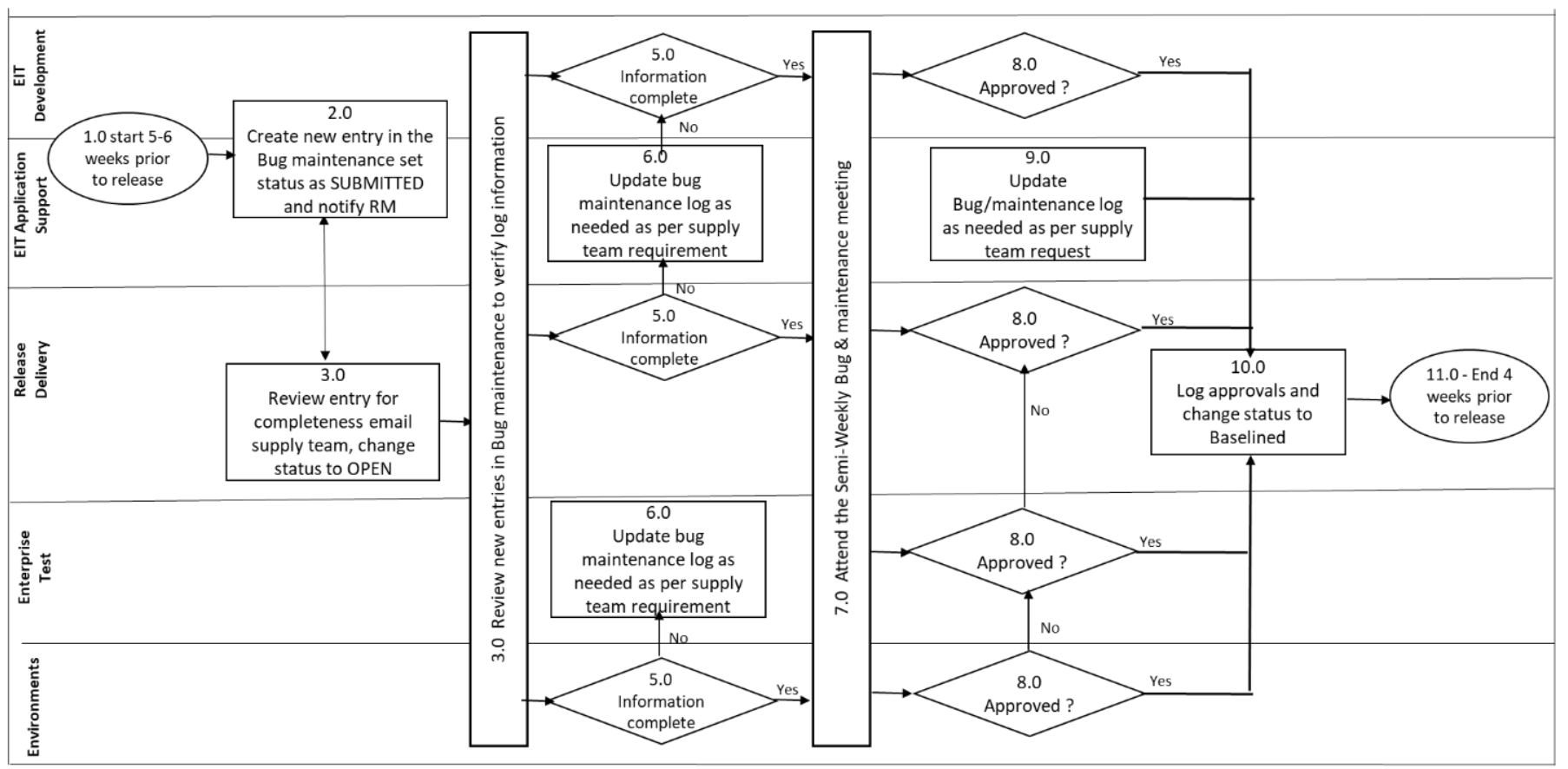

Fig 5: Maintenance and bug fixing

\begin{tabular}{|c|c|c|c|}
\hline $\begin{array}{l}1 \\
\text { / } \\
2\end{array}$ & $\begin{array}{l}\text { Applicati } \\
\text { on } \\
\text { Support } \\
\text { and/or } \\
\text { Develop } \\
\text { ment }\end{array}$ & a. & $\begin{array}{l}\text { START: Approximately 5-6 weeks } \\
\text { before a major or minor release, } \\
\text { Requestors must create a new Bug } \\
\text { or maintenance entry. } \\
\text { Requestor creates a new entry in } \\
\text { the Bug \& Maintenance Tracker in } \\
\text { SharePoint. } \\
\text { Complete all required information, } \\
\text { which includes: } \\
\text { i. Release Date: } \\
\text { ii. Bundle Name: } \\
\text { iii. Remedy Ticket } \\
\text { iv. \#/Description } \\
\quad \text { Impode/Configuration } \\
\text { v. Test impacted } \\
\text { applications } \\
\text { vi. Code Drop date } \\
\text { vii. Test Intake Request \# } \\
\text { viii. Assigned Test Lead. } \\
\text { ix. Set Status to: Submitted } \\
\text { x. Requestor name } \\
\text { Send email notification of item } \\
\text { entry to Release Management. List } \\
\text { the Bundle Name and Release } \\
\text { Date in the email notification. }\end{array}$ \\
\hline
\end{tabular}

\begin{tabular}{|c|c|c|c|}
\hline 3 & $\begin{array}{l}\text { Release } \\
\text { Managem } \\
\text { ent }\end{array}$ & b. & $\begin{array}{l}\text { Reviews new entry for } \\
\text { completeness of required } \\
\text { information. } \\
\text { i. If entry form is } \\
\text { incomplete, Release } \\
\text { Management will route it } \\
\text { back to the Requestor } \\
\text { If entry form is complete, } \\
\text { Release Management } \\
\text { advances to next steps. } \\
\text { Release Management changes the } \\
\text { status of the Bug/Maintenance } \\
\text { item in the log to: Open as that } \\
\text { indicates the item is ready to be } \\
\text { placed on the meeting agenda for } \\
\text { review. Mangement emails } \\
\text { Release Manageme } \\
\text { communications to the Bug \& } \\
\text { Maintenance Distribution list } \\
\text { asking supply teams to review and } \\
\text { ready their approvals. }\end{array}$ \\
\hline 4 & $\begin{array}{l}\text { Test } \\
\text { Manager }\end{array}$ & $\begin{array}{ll}\text { a. } & \text { Ass } \\
\text { b. } & \text { Tes } \\
& \text { Env }\end{array}$ & $\begin{array}{l}\text { igns a Test Lead or test resource. } \\
\text { t Resource will create a Test ID and } \\
\text { ironment Request for new entry. }\end{array}$ \\
\hline
\end{tabular}




\begin{tabular}{|c|c|c|}
\hline 5 & $\begin{array}{l}\text { Supply } \\
\text { Teams }\end{array}$ & $\begin{array}{l}\text { Review new entry in the Bug/Maintenance } \\
\text { log for completeness and further analysis. } \\
\text { a. Developer review to ensure all } \\
\text { information provided is accurate and } \\
\text { up-to-date and confirm capacity to } \\
\text { support. } \\
\text { b. Application Support review to ensure } \\
\text { all information provided is accurate and } \\
\text { up-to-date and confirm capacity to } \\
\text { support. } \\
\text { c. Enterprise Test review information } \\
\text { provided in Test ID to ensure all } \\
\text { information provided is accurate and } \\
\text { up-to-date and that the Test ID and } \\
\text { Environment have been added to the } \\
\text { log. Confirm team's capacity to } \\
\text { support. } \\
\text { d. Environments/Enterprise Test review } \\
\text { information provided in Test ID and } \\
\text { Environment Request and up-to-date } \\
\text { and confirm capacity to support. } \\
\text { e. Release Delivery reviews information } \\
\text { provided and consults with Application } \\
\text { Support to ensure all information } \\
\text { provided is accurate and up-to-date and } \\
\text { confirm Application Support's capacity } \\
\text { to support. }\end{array}$ \\
\hline 7 & $\begin{array}{l}\text { Supply } \\
\text { Teams } \\
\text { Release } \\
\text { Delivery } \\
\text { Release } \\
\text { Managem } \\
\text { ent }\end{array}$ & 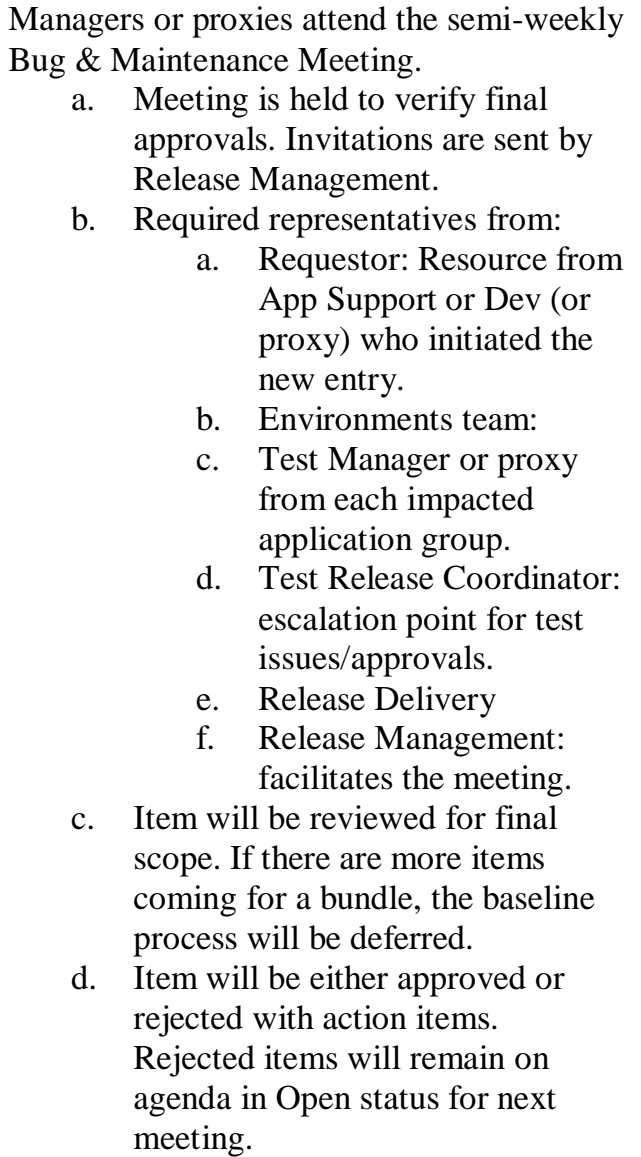 \\
\hline
\end{tabular}

\begin{tabular}{|c|l|l|}
\hline 8 & $\begin{array}{l}\text { Supply } \\
\text { Team } \\
\text { Managers }\end{array}$ & $\begin{array}{l}\text { If more information is needed from a } \\
\text { Supply Team at the meeting: } \\
\text { Email the Requestor of the new entry item. }\end{array}$ \\
\hline 9 & $\begin{array}{l}\text { Applicati } \\
\text { on } \\
\text { Support } \\
\text { and/or } \\
\text { Develop } \\
\text { ment }\end{array}$ & Update Bug/Maintenance. \\
\hline 1 & $\begin{array}{l}\text { Release } \\
\text { Managem } \\
\text { ent }\end{array}$ & $\begin{array}{l}\text { Enter approval information into } \\
\text { Bug/Maintenance Log and change status to: } \\
\text { Baselined. Items that have not met the } \\
\text { criteria to be baselined will be moved to the } \\
\text { following month's agenda. Add the } \\
\text { Baselined entry to the Release Plan. }\end{array}$ \\
\hline
\end{tabular}

\section{DEPLOYMENT PLANNING}

The process of developing a plan of deployment requires the provision of a schedule of deployment, identification of the dependencies that are technical for implementation (Stadler et al., 2019), identification of the dependencies that are technical for the deployment of pre-production.

1) Communication involves the maintenance of the changes impacted-training people on the changes and communication within massive releases.

2) Agreement schedules multiple stake holders.

3) Identification of releases and mitigation of the possible risk factors.

4) Scheduling controlled environments of transition.

5) Agreements on the entry release and the criteria of exit.

\section{A. Pre Deployment Process}

Preparation for deployment includes assigning the resources to perform the deployment activities.

1) Implementation plan-Deployment steps agreed and signed off by Operations team

2) Deployment timelines has been agreed and interdependencies identified

3) Mobilizing Operations team for the deployment

4) Arranging release notes walkthroughs for only impacted components with L2 and L3 teams and identifying the gaps

5) Conducting production schedule walkthroughs with 12 and $\mathrm{L} 3$ resources

6) Communicate Service Desk and Support staff on the target deployment and outages

7) Communicate the Target Impacted groups on, how the change impacts them

8) Final Release package moved under control of Configuration Management with version control

9) Preparing the Environment- Taking Backup, Port configurations etc, prior to deployment 
10) Delivering production schedule documents and communication plan to all the stakeholders involved in the release.

11) Provide escalation contacts in the Production schedule.
12) Release manager to follow the Go/No-go decisions taken by release team and business teams for the production change.

13) Release manager to arrange the L2 resources for rollback decisions taken by release manager.

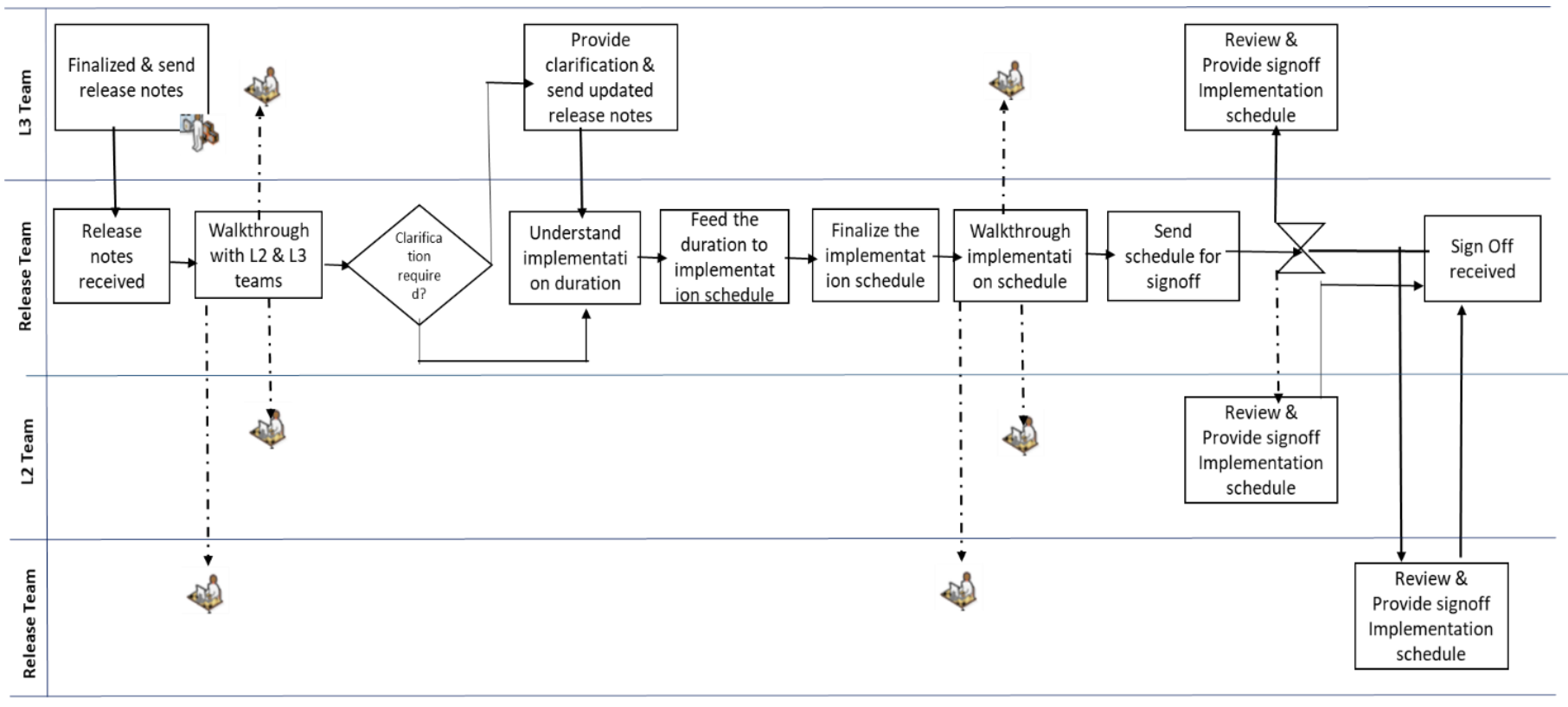

Fig 6: Pre production deployment

\section{B. Deployment Process}

Deployment involves carrying out the activities as defined in the Implementation plan. This includes

1) Manage all pre deployment and backup activities as identified in the implementation schedule

2) Communicate to helpdesk, Service desks and other stakeholders about the commencement of the deployment window and outages

3) Obtain the receipt from helpdesk

4) Check with service desk if there are any open request/tickets on production environment before commencing the main deployment

5) If any request/tickets found must be notified to release management team

6) Participate in the Go/No-Go decision meeting and inform about the decision to all identified stakeholders

7) Resolve deployment issues found during the deployment by effectively coordinating with required resources

8) Recording any incidents, unexpected events, issues or deviations from the plans 


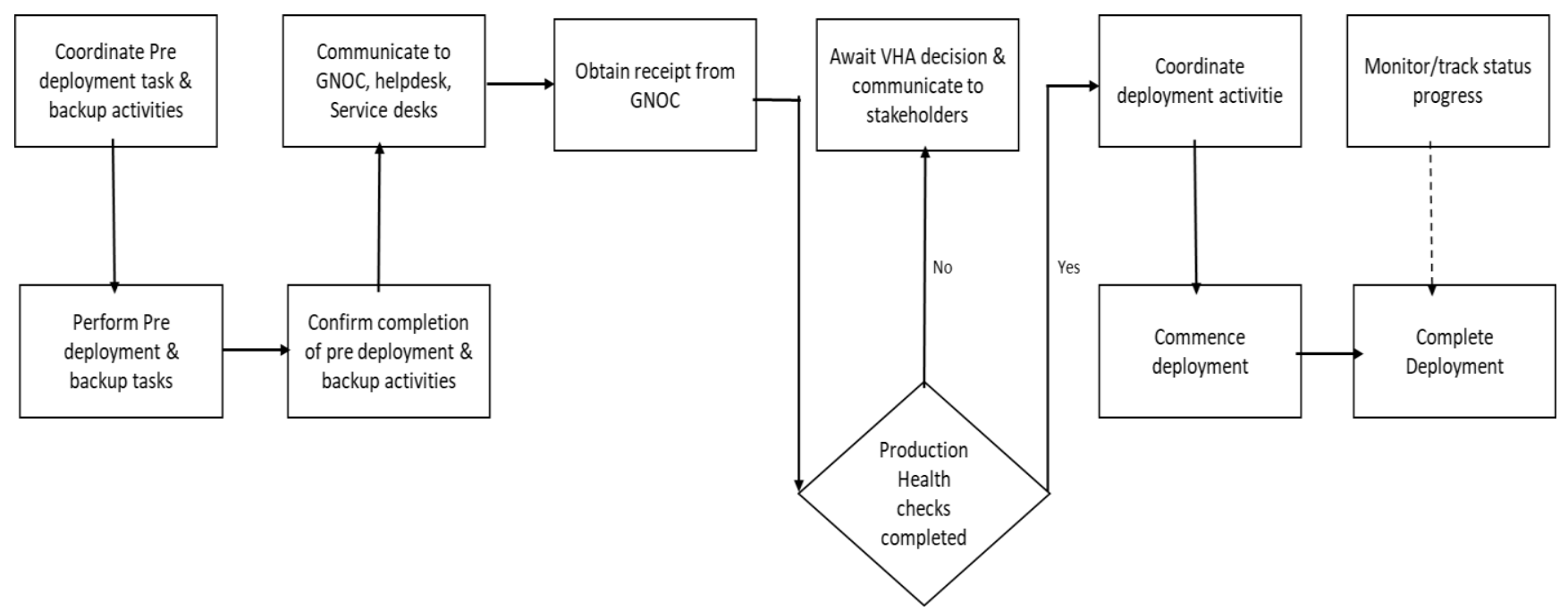

Fig 7: Production deployment

\section{Post Deployment Process}

Post deployment activities, it is important to verify that package has been installed properly on the target environment and at the desired location. The tests include.

1) Perform audit -compare against the Deployed baseline vs Planned Baseline

2) Perform system Health checks that all the services, interfaces are performing as desired

3) Operations team are prepared to operate in normal and emergency situations

4) Perform PVT as per guidelines given in release notes

5) Provide Log files to L3 for the verification and take the confirmation for the same

6) Support Cut Over verification test(CVT) phase. L2 resources available for hot fixes and support activities

7) Support and coordinate post deployment defect fixes

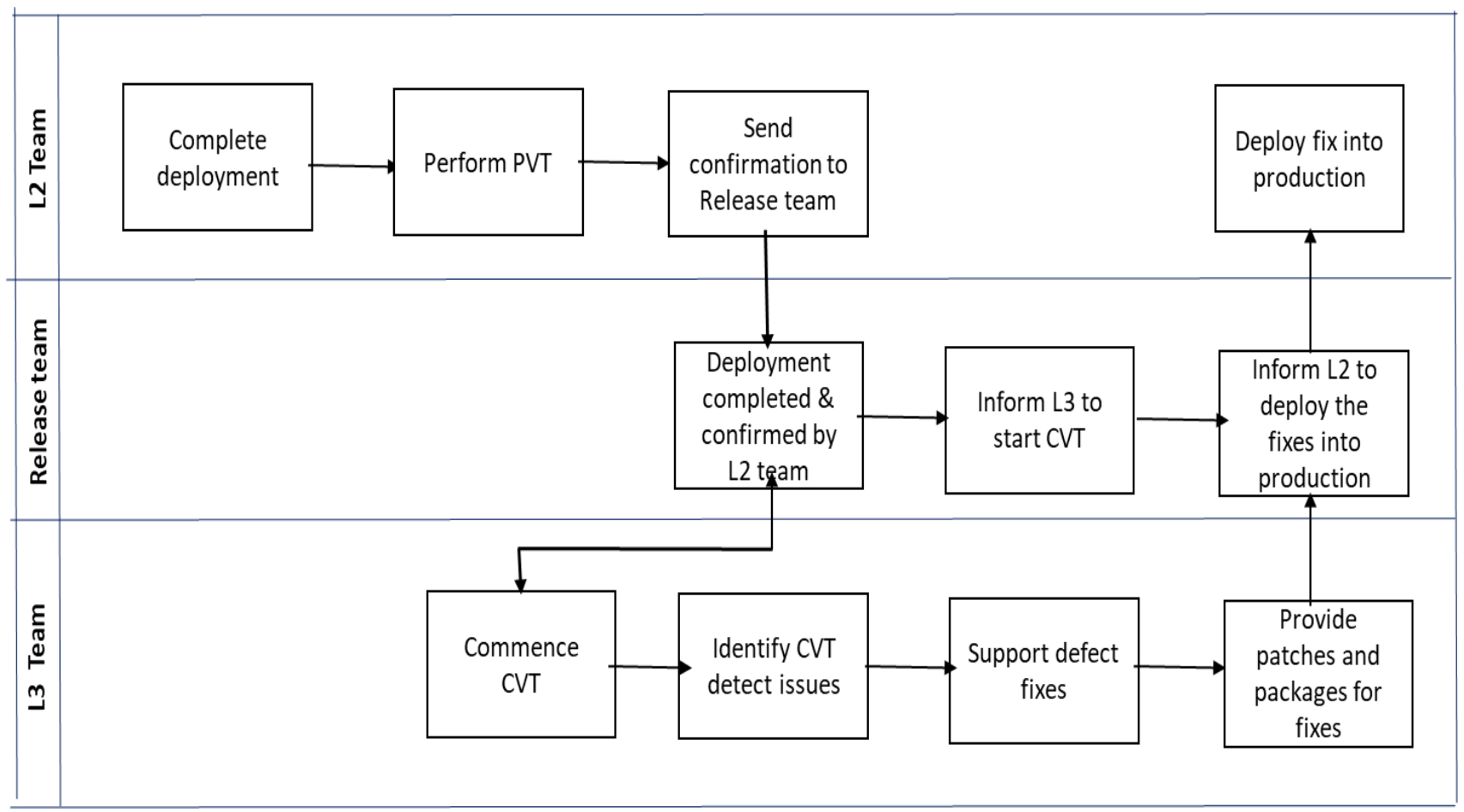

Fig 8: Post Production deployment 


\section{CONCLUSION}

Due to continuous and dynamic changes in business the need of an organization to adopt to market's changing trends are resulting in implementing new software's, hardware, patches, enhancements, resulting to have their release and deployment process managed very effectively as this involves a transition to living environment that are in operation.

Release and Deployment is a process that ensures that the implementation and use of new software meet the requirements and standards that have been set in the organization. The software developers are always specific on the procedure and standards to be met. In the Release Management cycle, eight steps have been accepted as being vital in the promotion of the standard way of improving the quality and ensuring that the process meets its objectives. However, the identification of the gap needs to be very particular. In developing a system that can be relied upon by various players in the industry, it remains critically essential in handling the design and software issue. The association between the Release and Deployment procedures and the safety of the software and hardware remains critically essential in the handling of the main issues.

\section{GLOSSARY OF TERMS}

\begin{tabular}{|l|l|}
\hline Acronym & Full Name \\
\hline RR & Release result \\
\hline Capex & Capital expenditure \\
\hline PM & Project Manager \\
\hline PMO & Project Management Office \\
\hline PMP & Project Management Plan \\
\hline PT & Project Team \\
\hline PVT & Product Verification testing \\
\hline BAU & Business As Usual \\
\hline CVT & Cutover Verification Testing \\
\hline RASR & Release and Service Request \\
\hline GNOC & Global Network Operations Centre \\
\hline SLA & Service Level Agreements \\
\hline SME & Subject Matter Expert \\
\hline
\end{tabular}

\section{REFERENCES}

[1] Bacher, U., Lueck, E., Raspl, S., \& Spatzier, T. (2020). U.S. Patent Application No. 16/744,780.

[2] Guo, J., Li, G., Klein, M. D., Fu, Z., Song, B., \& Hua, W. (2016). U.S. Patent No. 9,235,409. Washington, DC: U.S. Patent and Trademark Office.

[3] Jubran, M. E., Gershaft, A., \& Libenson, M. (2018). U.S. Patent No. 9,916,133. Washington, DC: U.S. Patent and Trademark Office.

[4] Manglik, G., Sriram, V. N., Ganguly, S., Sah, R., \& Mukherjee, S. (2016). U.S. Patent No. 9,292,343. Washington, DC: U.S. Patent and Trademark Office.

[5] Mantripragada, N. K., Mungi, A., Sodhi, M. S., \& Viswanathan, R. (2016). U.S. Patent No. 9,383,984. Washington, DC: U.S. Patent and Trademark Office.

[6] Passmore, E. (2016). Pre-Release and Deployment Checklist. In Migrating Large-Scale Services to the Cloud (pp. 67-73). Apress, Berkeley, CA.
Pillay, S., Sumin, A., \& Burnside, P. L. (2018). U.S. Patent No. 9,898,269. Washington, DC: U.S. Patent and Trademark Office.

Shanmugasundaram, P., \& Sarojini, B. (2018). An Overview of Release and Deployment Management Strategy. International Journal of Pure and Applied Mathematics, 118(9), 5-12.

Singh, K., Shrivastava, A., \& Muneebuddin, M. (2017). U.S. Patent Application No. 15/075,216.

0] Stadler, C., Wenige, L., Martin, M., Tramp, S., \& Junghanns, K. (2019). RDF-based Deployment Pipelining for Efficient Dataset Release Management. In SEMANTICS Posters\&Demos.

\section{First Authors Profile}

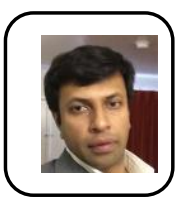

Maqhbool Jameel Ahmed is presently working as a Director in Supply Chain Management \& Digital Transformation in Information Technology sector. He has overall 15 years of experience in the area of Business Enterprise System Implementation and Operational support. $\mathrm{He}$ is highly experienced in Enterprise Resource Planning and led multiple large sized client to transform their IT platform by implementing ERP's-SAP, Oracle, Digital platforms. He has guided graduate and post graduate students on Enterprise resource planning applications $\mathrm{He}$ has extensive experience in IT infrastructure management, Project management, Project analysis, Cost control, Resource management, Financial management, critical analysis, problem resolution and Quality assurance.

\section{Second Authors Profile}

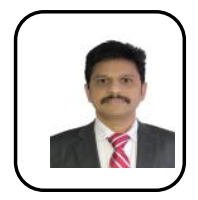

Dr. K. Phani Raja Kumar is presently working as a Project Manager in Supply Chain Management \& Digital Transformation in Information Technology sector since 2008. He was working in Ordnance Factory Medak, Min of Defense, India for $11+$ years in the area of Mechanical/Manufacturing Engineering. He has guided post graduate students and worked in China on Industrial Automation projects. $\mathrm{He}$ is highly experienced in Mechanical/Industrial engineering and Information Technology of Automobile, Semiconductor, Manufacturing and Telecom sectors. He is also experienced in new age Digital Technologies and Business Products Transformation 